\title{
Sequence of Fuzzy Topographic Topological Mapping
}

\author{
Siti Suhana Jamaian ${ }^{1, *}$, Tahir Ahmad ${ }^{1, *}$ and Jamalludin Talib ${ }^{2}$ \\ 1 Ibnu Sina Institute for Fundamental Science, \\ 2 Fuzzy Research Group (FRG), Department of Mathematics, \\ Faculty of Science, Universiti Teknologi Malaysia 81310 Skudai , Johor, Malaysia \\ * Author to whom correspondence should be addressed; E-mail: suhana_jamaian@yahoo.com, tahir_22@hotmail.com and \\ c_maths@ibnusina.utm.my
}

Received: 12 November 2008

http://dx.doi.org/10.11113/mjfas.v4n2.51

\section{ABSTRACT}

Fuzzy Topographic Topological Mapping, shortly FTTM, is a model for solving neuromagnetic inverse problem. FTTM consist of four topological spaces and connected by three homeomorphisms. FTTM 1 and FTTM 2 were developed to present 3-D view of an unbounded single current source and bounded multicurrent sources, respectively. Liau Li Yun (2006) showed that FTTM 1 and FTTM 2 are homeomorphic and this homeomorphism will generate another 14 FTTM. She then conjectured if there exist $n$ elements of FTTM then the numbers of new elements are $n 4-n$. The 1purpose of this paper is to study the geometrical features of FTTM. In the process, several definitions were developed which may be used to prove the conjecture. This paper will show the proof of the conjecture and their extension result.

\section{| Algebraic progression | Geometrical object | Mathematical Induction | Topological space |}

\section{Introduction}

The human brain (Figure 1a) is the most important structure in our body. It is also the most complex organized structure known to exist. There are four lobes in both halves of the cortex: frontal, pariental, temporal and occipital. The outermost layer of the brain is called the cerebral cortex. The cerebral cortex has a total surface area of about $2500 \mathrm{~cm}^{2}$, folded in a complicated way, so that it fits into the cranial cavity formed by the skull of the brain. There are at least $10^{10}$ neurons in the cerebral cortex [3].

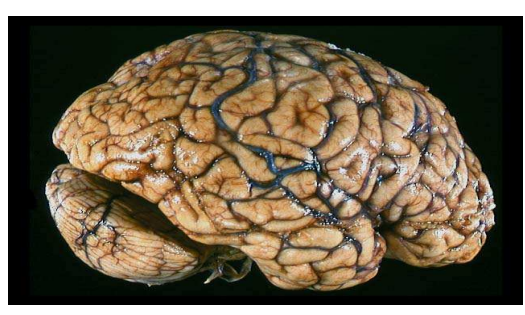

(a)

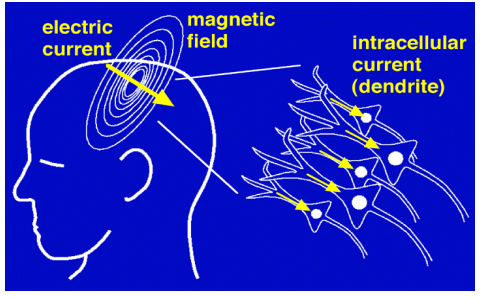

(b)

Figure 1: (a) Human Brain (b) Neuro Magnetic Field 
These neurons are the active units in a vast signal-handling network. When information is being processed, small currents flow in the neural system and produce a weak magnetic field (Fig. 1b), which can be measured non-invasively by a SQUID (Superconducting Quantum Interference Device) magnetometer. Magnetoencephalography (MEG) is a recording of magnetic fields produced by electrical activity of the neurons in the brain. MEG is completely non-invasive and non-hazardous [3]. When an epileptic patient is having an epileptic fit, the neurons in the brain of the patient produce four times current as compared to normal brain. The current source is considered as the epileptic foci.

Magnetic field readings obtained from SQUID give information for the process to determine location, direction and magnitude of a current source. This is called neuromagnetic inverse problem. Currently there is only a method for solving this problem, namely Bayesian that needs a priori information (data based model) and it is time consuming [9]. By using Bayesian, forward calculation is used to calculate the magnetic field caused by the current dipole at every possible point.

The best location of the current source is determined by minimizing the sum of the squares of the difference between the measured and the calculated value similar to the least squares method. Then, a point with a minimum least squares method is the location of a current source [2]. On the other hand, FTTM is a novel model for solving neuromagnetic inverse problem [7]. It does not need a priori information and it is not time consuming. The development of FTTM has been reported in sequentially. Its initial development has been coined in [1], then followed by its initial performance in [7]. Its mathematical structure is compiled in [5], its algorithm is written in [2] and its performance is reported extensively in [8].

\subsection{Extended FTTM}

FTTM 2 is an extended model of FTTM1 as described in previous section. It is specifically designed to solve the inverse problem of multi current sources. The main difference between FTTM1 and FTTM2 is that FTTM1 uses the magnetic field data and it is applied to unbounded single current sources whilst FTTM2 uses the transformed data of magnetic fields (the image data) and it is applied to bounded single and multiple current sources.

FTTM2 can present a three-dimensional view of bounded multiple currents [10]. It consists of three algorithms that link between four components of the model. The four components are Magnetic Image Plane $(M I)$, Base Magnetic Image Plane (BMI), Fuzzy Magnetic Image Field (FMI) and Topographic Magnetic Image Field $(T M I)$ as shown in Figure 2.

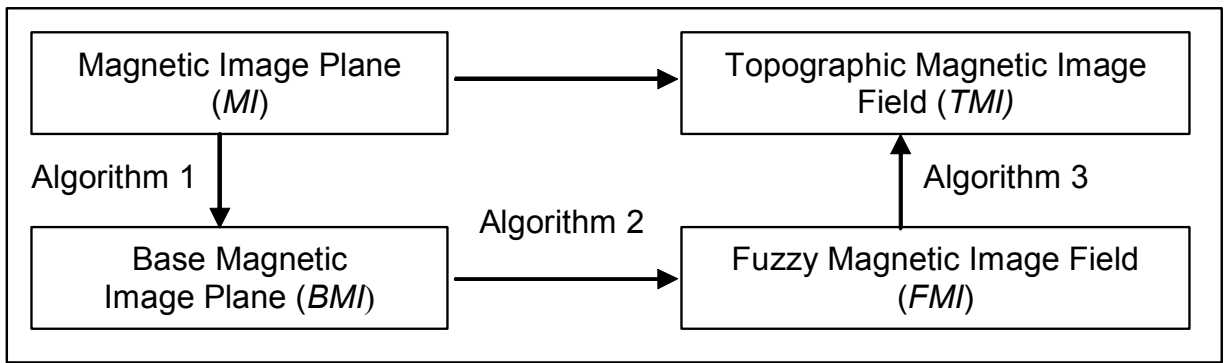

Figure 2: Fuzzy Topographic Topological Mapping Version 2 
In order to carry out the processes in FTTM 2, the magnetic fields data which initially lies on the Magnetic Contour Plane $(M C)$ are first analysed and then transformed to image processing data (gray levels) ranging from 0 (represents black image) to 255 (white image). This is to expand the narrow range of magnetic fields data to a wider range. In doing so, it is expected that the small changes in the magnetic fields can be detected. Hence, this will facilitate the identification of the underlying current sources which generated the measured magnetic fields data.

FTTM Version 1 as well as FTTM Version 2 are specially designed to have equivalent topological structures between its components. In other words, a homeomorphism between each component of FTTM Version 1 as well as FTTM Version 2 exists.

\subsection{Generalized FTTM}

Generally, FTTM can be represented as follows:

$\mathrm{FTTM}=\{(M, B, F, T): M \cong B \cong F \cong T\}$

$\left(M^{\prime}, B^{\prime}, F^{\prime}, T^{\prime}\right) \in \mathrm{FTTM}$ means that it satisfy the conditions of $M, B, F$ and $T$ respectively as given in [5] and $M^{\prime} \cong B^{\prime}, B^{\prime} \cong F^{\prime}$, and $F^{\prime} \cong T^{\prime}$.

FTTM 1 and FTTM 2 are examples of elements of FTTM. The fact that FTTM 1 and FTTM 2 are homeomorphic componentwise (see Figure 3), there are at least another 14 elements of FTTM that can be identified easily. These 14 elements of FTTM are as follows:

$(M C, B M, F M, T M I),(M C, B M, F M I, T M),(M C, B M I, F M, T M),(M I, B M, F M, T M),(M C, B M, F M I, T M I)$, (MC, BMI, FMI, TM), (MI, BMI, FM, TM), (MI, BM, FM, TMI), (MI, BM, FMI, TM), (MC, BMI, FM, TMI), (MC, BMI, FMI, TMI), (MI, BM, FMI, TMI),(MI, BMI, FM, TMI), and (MI, BMI, FMI, TM).

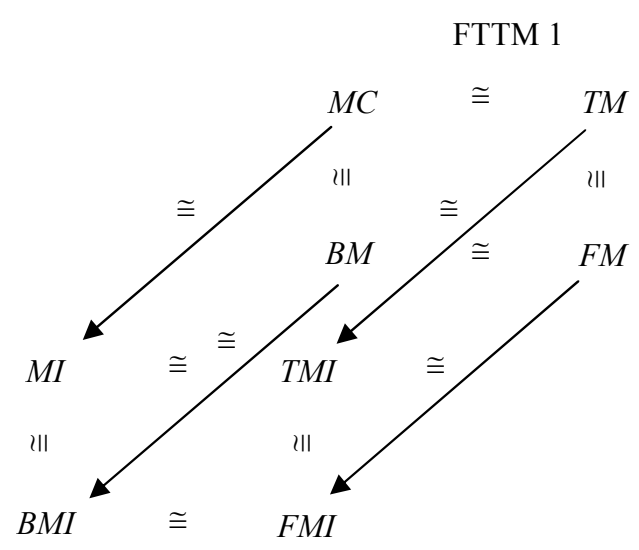

FTTM 2

Figure 3: Homeomorphisms between FTTM 1 and FTTM 2 
Li Yun in her Phd thesis (2006) [6] proposed the following conjecture.

Conjecture: If there exist $n$ elements of FTTM illustrated as

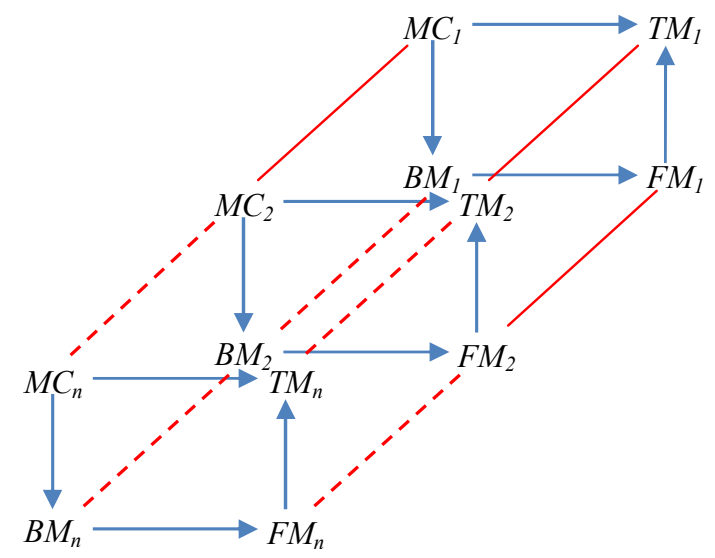

Figure 4: FTTM $_{n}$

then the numbers of new elements that can be generated are $n^{4}-n$ elements.

Even though it seems mathematical induction is most likely can be used to prove the conjecture, unfortunately it cannot be used in this particular case. This is due to the fact that Figure 4 is a geometrical object while $n^{4}-n$ is an algebraic expression. Because of this reason, we need to deduce some geometrical features such vertices, faces, edges and cubes or others out of sequence of FTTMs as given in Figure 4. These efforts hopefully will help to prove the conjecture.

\section{Materials and Methods}

\subsection{Sequence of FTTM}

In order to extract some geometrical features of FTTM, we need to define on how our FTTMs will be arranged.

Definition 1: $\quad$ Sequence of FTTM

Let $\mathrm{FTTM}_{i}=\left(M C_{i}, B M_{i}, F M_{i}, T M_{i}\right) \ni M C_{i}, B M_{i}, F M_{i}, T M_{i}$ are topological space with $M C_{i} \cong B M_{i} \cong F M_{i} \cong T M_{i}$. Set of $\mathrm{FTTM}_{i}$ denoted by FTTM $=\left\{\mathrm{FTTM}_{i}: i=1,2,3, . ., n\right\}$. Sequence of $n \mathrm{FTTM}_{i}$ of FTTM is FTTM ${ }_{1} \mathrm{FTTM}_{2}$, $\mathrm{FTTM}_{3}, \ldots, \mathrm{FTTM}_{\mathrm{n}} Э M C_{i} \cong M C_{i+1}, B M_{i} \cong B M_{i+1}, F M_{i} \cong F M_{i+1}, T M_{i} \cong T M_{i+1}$. 


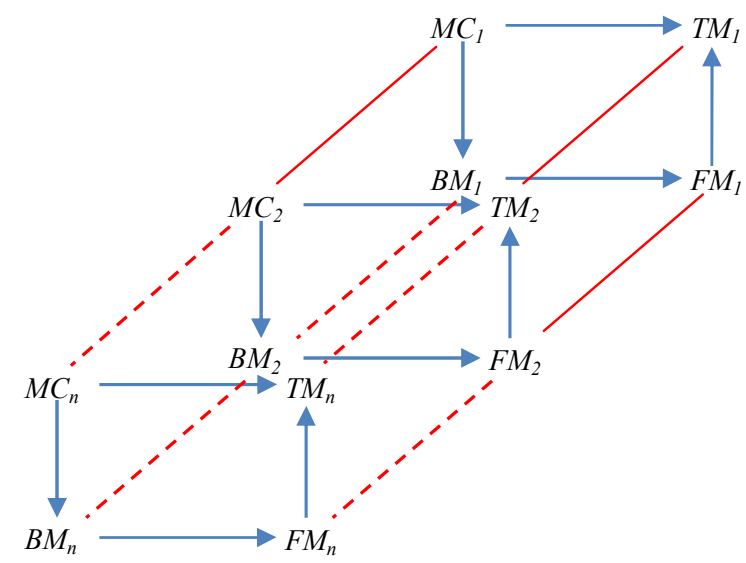

Figure 5: Sequence of FTTM

As a start, let us look at FTTM 1, FTTM 2, FTTM 3 and FTTM 4 respectively.

$\underline{\text { FTTM }}_{1}$

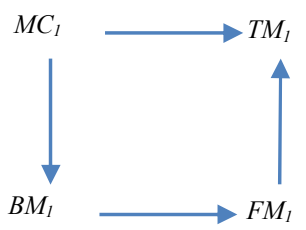

Figure 6: FTTM $_{1}$

FTTM 1 can be viewed generally as a square and without loss of generality we can think $M C, B M, F M$ and $T M$ as vertices and the homeomorphism, i.e, $M C \cong B M, B M \cong F M, F M \cong T M$ and $M C \cong T M$, as edges. Therefore, FTTM 1 has 4 vertices, 4 edges and 1 face.

$\underline{\text { FTTM }_{2}}$

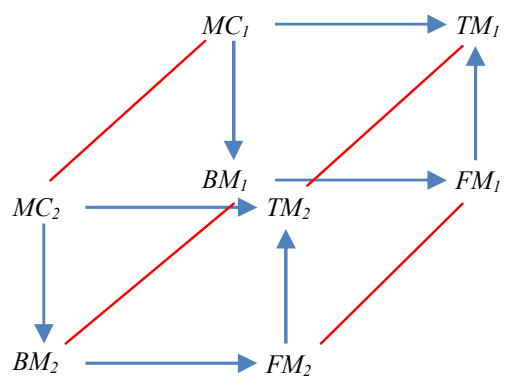

Figure 7: FTTM $_{2}$ 
Similarly FTTM 2 will give us 8 vertices, 12 edges, 6 faces and 1 cube. Generally a cube is a combination of 2 FTTM.

$\underline{\mathrm{FTTM}}_{3}$

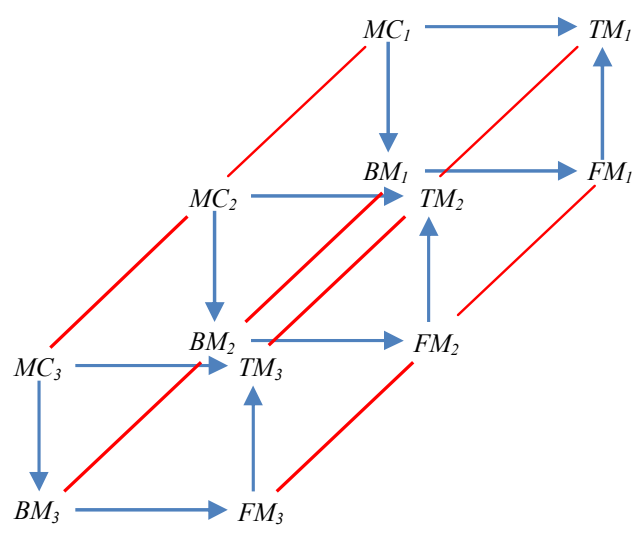

Figure 8: $\mathrm{FTTM}_{3}$

FTTM 3 consists of 12 vertices, 24 edges, 15 faces and 3 cubes.

\section{$\underline{\text { FTTM }}_{4}$}

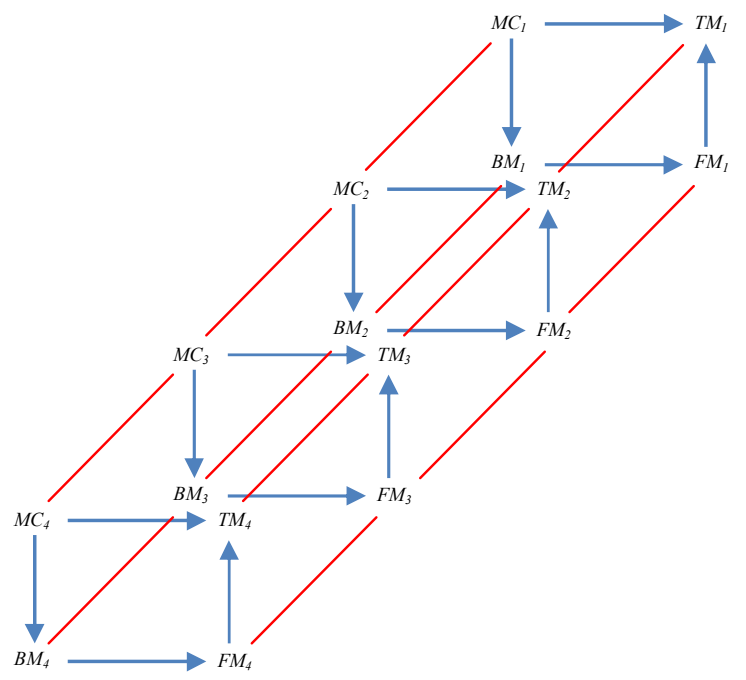

Figure 9: FTTM $_{4}$ 
FTTM 4 has 16 vertices, 28 edges, 16 faces and 6 cubes.

Consequently, we can observe some patterns for vertices, edges, faces and cubes emerging as listed in the following table.

Table 1: Vertices, edges, faces and cubes for sequence of FTTM

\begin{tabular}{|c|c|c|c|c|}
\hline FTTM $_{n}$ & Vertices & Edges & Faces & Cubes \\
\hline 1 & 4 & 4 & 1 & 0 \\
\hline 2 & 8 & 12 & 6 & 1 \\
\hline 3 & 12 & 20 & 11 & 3 \\
\hline 4 & 16 & 28 & 16 & 6 \\
\hline 5 & 20 & 36 & 21 & 10 \\
\hline 6 & 24 & 44 & 26 & 15 \\
\hline 7 & 28 & 52 & 31 & 21 \\
\hline 8 & 32 & 60 & 36 & 28 \\
\hline 9 & 36 & 68 & 41 & 36 \\
\hline 10 & 40 & 76 & 46 & 45 \\
\hline
\end{tabular}

Furthermore, we need the following definition to specify the ' $k$ th-term' of a sequence of FTTM ${ }_{n}$.

Definition 2: $\quad$ Term of FTTM

$k$-FTTM $\mathrm{n}$ is the $k$ term FTTM of a sequence of FTTM $_{\mathrm{n}}$ for $n \geq k$.

For example, 1-FTTM 3 , 2-FTTM 3 and 3-FTTM 3 are given as follows.

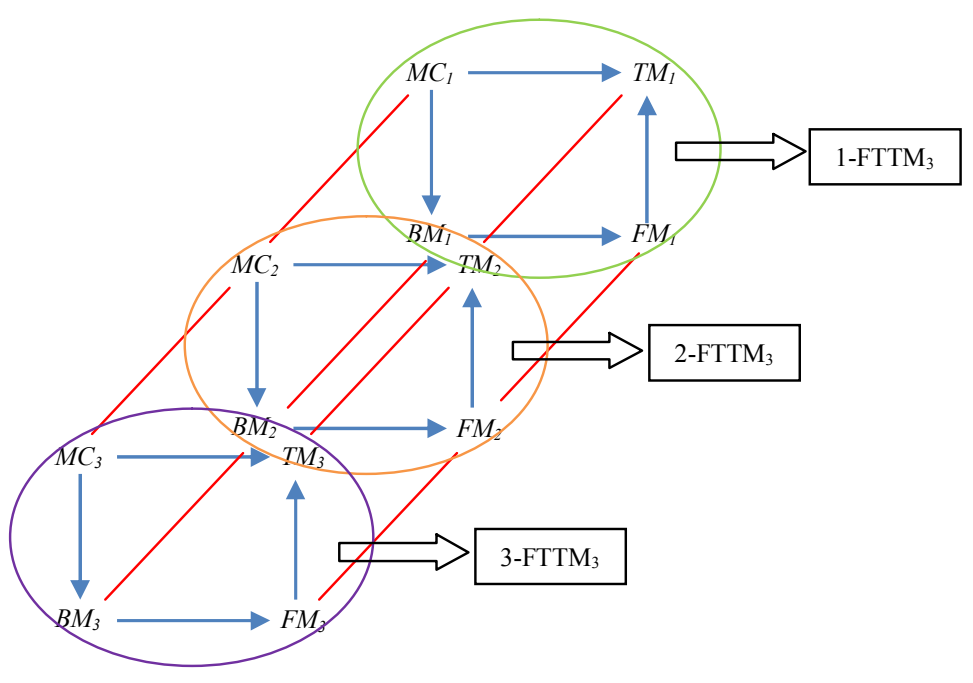

Figure 10: $\mathrm{FTTM}_{3}$ and its terms 


\subsection{Geometrical Features of Sequence of FTTMs}

By defining sequence of FTTMs as given in the previous section, considering Table 1 and invoking to arithmetic sequence, we can have the following definitions of special sequences of features obtained from FTTMs immediately which are analogous to the definition of Fibonacci sequence given in [4].

Definition 3: $\quad$ Sequence of Vertices of FTTM The sequence of vertices for $\mathrm{FTTM}_{\mathrm{n}}$ which is $v \mathrm{FTTM}_{1}, v \mathrm{FTTM}_{2}, v \mathrm{FTTM}_{3}, \ldots$ are defined recursively by the equation $v \mathrm{FTTM}_{\mathrm{n}}=v \mathrm{FTTM}_{\mathrm{n}-1}+4$ for $n \geq 1$ and $v \mathrm{FTTM}_{0}=0$.

Definition 4: $\quad$ Sequence of Edges of FTTM $_{n}$ The sequence of edges for $\mathrm{FTTM}_{\mathrm{n}}$ which is $e \mathrm{FTTM}_{1}, e \mathrm{FTTM}_{2}, e \mathrm{FTTM}_{3}, \ldots$ are defined recursively by the equation $e \mathrm{FTTM}_{\mathrm{n}}=e \mathrm{FTTM}_{\mathrm{n}-1}+8$ for $n>1$ and $e \mathrm{FTTM}_{1}=4$.

Definition 5: $\quad$ Sequence of Faces of FTTM

The sequence of faces in $\mathrm{FTTM}_{\mathrm{n}}$ is $f \mathrm{FTTM}_{1}, f \mathrm{FTTM}_{2}, f \mathrm{FTTM}_{3}, \ldots$ are defined recursively by the equation $f \mathrm{FTTM}_{\mathrm{n}}=f \mathrm{FTTM}_{\mathrm{n}-1}+5$ for $n>1$ and $f \mathrm{FTTM}_{1}=1$.

Definition 6: $\quad$ Sequence of Cubes of $\mathrm{FTTM}_{n}$ The sequence of cubes for $\mathrm{FTTM}_{\mathrm{n}}$ which is $\mathrm{FTTM}_{2 / 1}, \mathrm{FTTM}_{2 / 2}, \mathrm{FTTM}_{2 / 3}, \ldots$ are defined recursively by the equation $\mathrm{FTTM}_{2 / \mathrm{n}}=\mathrm{FTTM}_{2 / \mathrm{n}-1}+(\mathrm{n}-1)$ for $n \geq 1$ and $\mathrm{FTTM}_{2 / 0}=0$.

The definitions and some geometrical properties presented in Section 4 and 5 respectively are very important and will be used for the future work; i.e. proving conjecture 1 .

\section{Results and Discussion}

By examining cube in FTTM, we can realize that cube is come from the combination of two terms FTTM in FTTM $_{n}$ and will generate another 14 new elements of FTTM. Therefore, Definition 6 can be expressed as follows and Table 2 shows sequence of FTTM $_{2 / n}$ and its new elements.

Definition 7: $\quad$ Sequence of FTTM $_{2 / \mathrm{n}}$

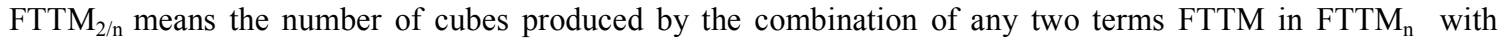
$\mathrm{FTTM}_{2 / 1}=0$. Hence, $\mathrm{FTTM}_{2 / 2}=1, \mathrm{FTTM}_{2 / 3}=3, \mathrm{FTTM}_{2 / 4}=6$ and in general;

$\mathrm{FTTM}_{2 / \mathrm{n}}=\mathrm{FTTM}_{2 / \mathrm{n}-1}+(\mathrm{n}-1)$ for all $\mathrm{n}>1$.

Table 2: Sequence of FTTM $_{2 / n}$

\begin{tabular}{|c|c|c|}
\hline FTTM $_{\mathrm{n}}$ & FTTM $_{2 / \mathrm{n}}$ & 14 FTTM $_{2 / \mathrm{n}}$ \\
\hline FTTM $_{1}$ & 0 & 0 \\
\hline FTTM $_{2}$ & 1 & 14 \\
\hline FTTM $_{3}$ & 3 & 42 \\
\hline FTTM $_{4}$ & 6 & 84 \\
\hline FTTM $_{5}$ & 10 & 140 \\
\hline FTTM $_{6}$ & 15 & 210 \\
\hline FTTM $_{7}$ & 21 & 294 \\
\hline FTTM $_{8}$ & 28 & 392 \\
\hline FTTM $_{9}$ & 36 & 504 \\
\hline FTTM $_{10}$ & 45 & 630 \\
\hline
\end{tabular}


Cube in $\mathrm{FTTM}_{\mathrm{n}}$ can also be produced from the combination of three terms or three different versions of FTTM in FTTM $_{n}$. Then, the combination will generate another 36 new elements of FTTM. Follows is the general definition and Table 3 demonstrates sequence of $\mathrm{FTTM}_{3 / \mathrm{n}}$ and its new elements

Definition 8: $\quad$ Sequence of FTTM $_{3 / \mathrm{n}}$

$\mathrm{FTTM}_{3 / \mathrm{n}}$ means the number of cubes produced by the combination of any three terms FTTM in FTTM $\mathrm{Fith}_{\mathrm{n}}$ $\mathrm{FTTM}_{3 / 1}=0, \mathrm{FTTM}_{3 / 2}=0$. Hence, $\mathrm{FTTM}_{3 / 3}=1, \mathrm{FTTM}_{3 / 4}=4, \mathrm{FTTM}_{3 / 5}=10$ and in general;

FTTM $_{3 / \mathrm{n}}=$ FTTM $_{3 / \mathrm{n}-1}+$ FTTM $_{2 / \mathrm{n}-1}$ for all $\mathrm{n}>1$.

Table 3: Sequence of FTTM $3 / n$

\begin{tabular}{|c|c|c|}
\hline FTTM $_{\text {n }}$ & FTTM $_{3 / \mathrm{n}}$ & 36 FTTM $_{3 / \mathrm{n}}$ \\
\hline FTTM $_{1}$ & 0 & 0 \\
\hline FTTM $_{2}$ & 0 & 0 \\
\hline FTTM $_{3}$ & 1 & 36 \\
\hline FTTM $_{4}$ & 4 & 144 \\
\hline FTTM $_{5}$ & 10 & 360 \\
\hline FTTM $_{6}$ & 20 & 720 \\
\hline FTTM $_{7}$ & 35 & 1260 \\
\hline FTTM $_{8}$ & 56 & 2016 \\
\hline FTTM $_{9}$ & 84 & 3024 \\
\hline FTTM $_{10}$ & 120 & 4320 \\
\hline
\end{tabular}

We have introduced that two and three terms FTTM in $\mathrm{FTTM}_{\mathrm{n}}$ can produce cubes. By extending the number of combination terms of FTTM to four, cube can also be produced and 24 new elements will be generated. Therefore, Definition 9 can be developed as following and Table 4 presents Sequence of FTTM $4 / \mathrm{n}$ and its new elements.

Definition 9: $\quad$ Sequence of FTTM $_{4 / \mathrm{n}}$

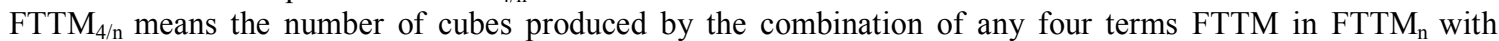
$\mathrm{FTTM}_{4 / 1}=\mathrm{FTTM}_{4 / 2}=\mathrm{FTTM}_{4 / 3}=0$. Hence, $\mathrm{FTTM}_{4 / 4}=1, \mathrm{FTTM}_{4 / 5}=5, \mathrm{FTTM}_{4 / 6}=15$ and in general;

FTTM $_{4 / \mathrm{n}}=$ FTTM $_{4 / \mathrm{n}-1}+$ FTTM $_{3 / \mathrm{n}-1}$ for all n $>1$.

Table 4: Sequence of FTTM $_{4 / \mathrm{n}}$

\begin{tabular}{|c|c|c|}
\hline FTTM $_{\mathrm{n}}$ & FTTM $_{4 / \mathrm{n}}$ & $2^{24 F T T M} 4 / \mathrm{n}$ \\
\hline FTTM $_{1}$ & 0 & 0 \\
\hline $\mathrm{FTTM}_{2}$ & 0 & 0 \\
\hline FTTM $_{3}$ & 0 & 0 \\
\hline $\mathrm{FTTM}_{4}$ & 1 & 24 \\
\hline FTTM $_{5}$ & 5 & 120 \\
\hline FTTM $_{6}$ & 15 & 360 \\
\hline $\mathrm{FTTM}_{7}$ & 35 & 840 \\
\hline FTTM $_{8}$ & 70 & 1680 \\
\hline FTTM $_{9}$ & 126 & 3024 \\
\hline FTTM $_{10}$ & 210 & 5040 \\
\hline
\end{tabular}


In reality, FTTM has four components which are $M C, B M, F M$ and $T M$. Furthermore, it has developed three different techniques to recognize cubes in FTTM which are $\mathrm{FTTM}_{2 / \mathrm{n}}, \mathrm{FTTM}_{3 / \mathrm{n}}$ and $\mathrm{FTTM}_{4 / \mathrm{n}}$. If we continue produce cubes from combination of five versions FTTM or more, one of the generated elements may $\left(M C_{1}, B M_{2}, F M_{3}, T M_{4}, k_{5}\right)$ with $k$ the new component of FTTM. It is impossible to continuing develop cube from the combination of five or more terms FTTM.

Consequently, the number of generating FTTM in a sequence of FTTM is the summation of three version cubes which $\mathrm{FTTM}_{2 / \mathrm{n}}, \mathrm{FTTM}_{3 / \mathrm{n}}$ and $\mathrm{FTTM}_{4 / \mathrm{n}}$ in FTTM . The coefficients for each version are 14, 36 and 24 respectively. The coefficients represent the number of new elements of FTTM from each combination to produce cube. Therefore, the equation given as follows and Table 5 indicate possibility to prove the conjecture proposed by Liau Li Yun, i.e.

Generating FTTM $_{n}=14$ FTTM $_{2 / n}+36$ FTTM $_{3 / n}+24$ FTTM $_{4 / n} \quad$ for $n>1$ with FTTM $_{2 / 1}=$ FTTM $_{3 / 1}=$ FTTM $_{4 / 1}=0$.

Table 5: Comparison generating $\mathrm{FTTM}_{n}$ to conjecture made by Liau Li Yun (2006)

\begin{tabular}{|c|c|c|c|c|c|}
\hline FTTM $_{n}$ & 14FTTM $_{2 / \mathrm{n}}$ & $36 \mathrm{FTTM}_{3 / \mathrm{n}}$ & $24 \mathrm{FTTM}_{4 / \mathrm{n}}$ & $\begin{array}{c}14 \mathrm{FTTM}_{2 / \mathrm{n}}+ \\
36 \mathrm{FTTM}_{3 / \mathrm{n}}+ \\
24 \mathrm{FTTM}_{4 / \mathrm{n}}\end{array}$ & $n^{4}-n$ \\
\hline FTTM $_{1}$ & $14(0)$ & $36(0)$ & $24(0)$ & 0 & 0 \\
\hline FTTM $_{2}$ & $14(1)$ & $36(0)$ & $24(0)$ & 14 & 14 \\
\hline FTTM $_{3}$ & $14(3)$ & $36(1)$ & $24(0)$ & 78 & 78 \\
\hline FTTM $_{4}$ & $14(6)$ & $36(4)$ & $24(1)$ & 252 & 252 \\
\hline FTTM $_{5}$ & $14(10)$ & $36(10)$ & $24(5)$ & 620 & 620 \\
\hline FTTM $_{6}$ & $14(15)$ & $36(20)$ & $24(15)$ & 1290 & 1290 \\
\hline $\mathrm{FTTM}_{7}$ & $14(21)$ & $36(35)$ & $24(35)$ & 2394 & 2394 \\
\hline FTTM $_{8}$ & $14(28)$ & $36(56)$ & $24(70)$ & 4088 & 4088 \\
\hline FTTM $_{9}$ & $14(36)$ & $36(84)$ & $24(126)$ & 6552 & 6552 \\
\hline FTTM $_{10}$ & $14(45)$ & $36(120)$ & $24(210)$ & 9990 & 9990 \\
\hline
\end{tabular}

Surprisingly, nonzero sequence of $\mathrm{FTTM}_{2 / \mathrm{n}}, \mathrm{FTTM}_{3 / \mathrm{n}}$ and $\mathrm{FTTM}_{4 / \mathrm{n}}$ obeys the third, fourth and fifth min diagonal of Pascal's Triangle respectively. 


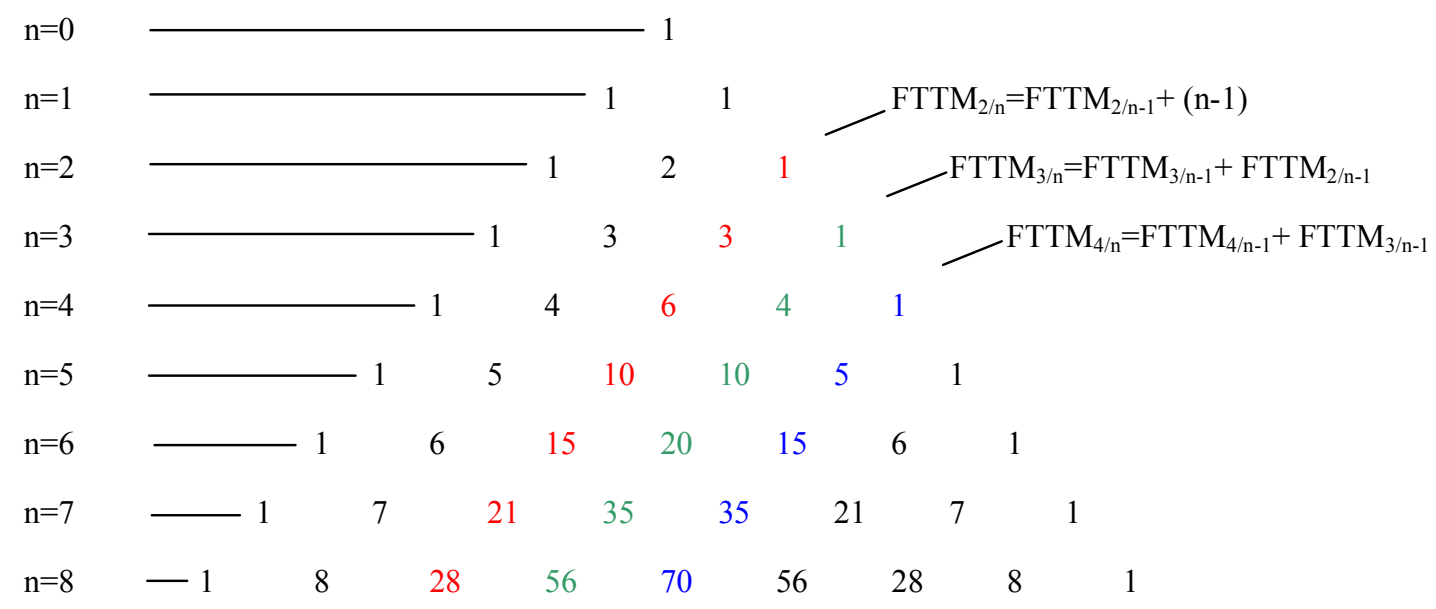

Figure 11: Sequence of $\mathrm{FTTM}_{2 / \mathrm{n}}, \mathrm{FTTM}_{3 / \mathrm{n}}$ and $\mathrm{FTTM}_{4 / \mathrm{n}}$ in Pascal's Triangle

\section{Conclusion}

In this paper, we study the geometrical features of sequence of FTTMs. In the process, several definitions were developed and geometrical properties were observed which have been used to prove Li Yun's conjecture. The unexpected results were encountered in this study which related to Pascal's Triangle.

\section{Acknowledgement}

The research is supported by Scientific Advancement Grant Allocation (SAGA) Fund. Ref. No: M 31 awarded by Ministry of Science and Technology (MOSTI) and Academy of Science Malaysia (ASM). We would like also to thank Institute of Pediatrics Hospital Kuala Lumpur \& Department of Neurosciences, School of Medical Sciences, HUSM for their assistance in this work as well as to the other members of Fuzzy Research Group (FRG), Department of Mathematics \& Ibnu Sina Institute for Fundamental Science Studies, UTM for their cooperation.

\section{References}

[1] Fauziah. Z., Tahir. A. and Rashidi Shah, A. (2000). Pemodelan Isyarat MEG. Proceeding of The $8^{\text {th }}$ Nasional Simposium of Mathematical Sciences. Kuala Terengganu: Universiti Putra Malaysia.

[2] Fauziah Zakaria (2002). Algorithma Penyelesaian Masalah Songsang Arus Tunggal Tak Terbatas MEG. Universiti Teknologi Malaysia: Tesis Sarjana.

[3] Hamalainen, M, Hari, R, Ilmoniemi, J. I., Knuutila, J and Lounasmaa, O. V. (1993). Magnetoencephalography - theory, instrumen andapplication to non-invasive studies of the networking human brain. Reviews on Modern Physics. 65 (2).430-434.

[4] Kenneth H. Rosen (2000). Elementary Number Theory and its Applications. $4^{\text {th }}$ ed. United State: AT \& T Laboratories. 
[5] Liau L. Y. (2001). Homeomorfisma $S^{2}$ Antara E $E^{2}$ Melalui Struktur Permukaan Riemann serta Deduksi Teknik Pembuktiannya bagi Homeomorfisma Pemetaan Topologi Topografi Kabur (FTTM). Universiti Teknologi Malaysia: Tesis Sarjana.

[6] Liau L. Y. (2006). Group-Like Algebraic Structures of Fuzzy Topographic Topological Mapping for solving Neuromagnetic Inverse Problem. Universiti Teknologi Malaysia: PhD Thesis.

[7] Tahir, A., Rashdi Shah, A., Fauziah, Z. and Liau. L. Y. (2000). Development of Detection Model for Neuromagnetic Fields. Proceeding of BIOMED. September 27-28. Kuala Lumpur: Universiti Malaya.119121.

[8] Tahir, A., Rashdi Shah, A., Fauziah, Z., Liau. L. Y. and Wan Eny Zarina, W. A. R. (2004). Homeomorphisms of Fuzzy opographic Topological Mapping (FTTM). Matematika, Jld.20, Bil. 2.

[9] Tarantola, A. and Vallete, B. (1982). Inverse problems:quest for information. J. Geophys. 50.

[10] Wan Eny Zarina, W. A. R., Tahir, A. and Rashidi Shah, A. (2002). Simulating The Neuronal Current Sources In The Brain. Proceeding BIOMED. September 27-28. Kuala Lumpur: Universiti Malaya. 